\title{
The FAS fluency test in Brazilian children and teenagers: executive demands and the effects of age and gender
}

\author{
Teste de fluência FAS em crianças e adolescentes brasileiros: demandas executivas \\ e efeitos de idade e gênero
}

Natália Martins Dias', Alessandra Gotuzo Seabra²

\begin{abstract}
The FAS Verbal Fluency Test is widely used in neuropsychological clinical services and research. This study investigated the contributions of different executive functions, age and gender to FAS test performance in a sample of children and teenagers divided into two groups: G1 comprised 263 children aged 6-10 years, and G2 comprised 150 teenagers aged 10-14 years. All participants were assessed using the Cancellation Attention Test, the Auditory Working Memory Test, the Visual Working Memory Test, the Semantic Generation Test, and the Trail Making Test, in addition to the FAS test. For G1, age, auditory working memory and shifting were predictors of FAS performance. For G2, gender, auditory working memory, shifting and inhibition comprised the FAS explanatory model. The study contributed to our understanding of which are the best predictor variables for the FAS test in a Brazilian sample and how executive demands change with age.
\end{abstract}

Keywords: executive function, neuropsychological tests, child development.

\section{RESUMO}

O Teste de Fluência Verbal FAS é amplamente utilizado na clínica e na pesquisa em neuropsicologia. O estudo investigou a contribuição de diferentes funções executivas (FE), idade e gênero para o desempenho no FAS em crianças e adolescentes, divididos em dois grupos: G1, 263 crianças, idade entre 6 e 10 anos, e G2, 150 adolescentes, idade entre 10 e 14 anos. Os participantes foram avaliados com o Teste de Atenção por Cancelamento, Teste de Memória de Trabalho Auditiva, Teste de Memória de Trabalho Visual, Teste de Geração Semântica e Teste de Trilhas, além do FAS. Para G1, idade, memória de trabalho auditiva e alternância foram preditores do desempenho no FAS. Para G2, gênero, memória de trabalho auditiva, alternância e inibição compuseram o modelo explicativo. 0 estudo contribuiu para compreender quais são as melhores variáveis preditoras do FAS em uma amostra brasileira e como as demandas executivas mudam com a progressão da idade.

Palavras-chave: função executiva, testes neuropsicológicos, desenvolvimento infantil.

Verbal fluency tests, such as the Controlled Oral Word Association Test (COWAT), are among the five most used executive function (EF) assessment instruments in North America ${ }^{1}$. They have also been largely used and researched in Brazil ${ }^{2-7}$. These tests are designed to assess verbal fluency, which is one aspect of fluency ability, and are related to the capacity to execute behaviors rapidly, sequentially, and in accordance with certain rules ${ }^{3,8}$. Verbal fluency can be assessed by semantic and letter/phonemic paradigms in which the most commonly used letters are F-A-S ${ }^{9-11}$.

The FAS Verbal Fluency Test (FAS), like others based on the fluency paradigm, is considered to be a complex task because it is based on various EF processes. These include a set of abilities such as working memory, inhibition and cognitive flexibility, that allow us to control and regulate our behavior, including emotions and cognitions, and act in deliberate and

${ }^{1}$ Psychologist, PhD in Developmental Disorders. Invited Professor of Lato Sensu Post-graduation, Universidade Presbiteriana Mackenzie, Sao Paulo SP, Brazil. Post-doctoral student;

${ }^{2}$ Psychologist, PhD in Experimental Psychology, São Paulo University. Professor of the Developmental Disorders Program, Universidade Presbiteriana Mackenzie, Sao Paulo SP, Brazil.

Correspondence: Natália Martins Dias; Est. Municipal Nemésio Dário dos Santos s/n / Cx. Postal: 45 / Moenda; $13252-755$ Itatiba SP - Brasil; E-mail:natalia_mdias@yahoo.com.br

Support: This work was financed in part by the Fundo de Pesquisa do Mackenzie - MackPesquisa, FAPESP and CNPq.

Conflict of interest: There is no conflict of interest.

Received 05 April 2013; Received in final form 25 July 2013; Accepted 01 August 2013. 
functional ways ${ }^{3,8,12}$. In this sense, we can hypothesize that verbal fluency tests involve: maintaining and constantly updating working memory, picking the right stimulus or rule to guide the production of behaviors, inhibiting incorrect or already given answers, leveraging enough flexibility to generate new answers and to not reproduce the same behavior patterns, and continuously monitoring this production. Despite these assumptions and the already known relationship between EF and the FAS, the test is widely used in neuropsychological research and clinical applications, frequently without a clear understanding of what it actually measures.

Some studies can help to shed light on this subject. First, cognitive $^{13,14}$ and neuroimaging ${ }^{11}$ studies offer evidence that semantic and phonemic fluency ${ }^{15}$ tasks present differential and specific demands for their solutions. Second, particularly relevant for phonemic fluency tests, FAS performance in healthy elderly individuals has been related to verbal intelligence, speed, flexibility and semantic memory ${ }^{16}$. In adults, some evidence also suggests that switching, which involves a significant degree of inhibition and flexibility, is involved in phonemic fluency ${ }^{14}$, as well as the auditory subsystem of working memory ${ }^{13}$. Thus, the literature emphasizes that phonemic fluency tests can be influenced by various cognitive processes, such as intelligence, working memory, flexibility, vocabulary, attention, inhibitory control and self-monitoring $^{3,8}$. Furthermore, other factors can also influence verbal fluency performance: for example, performance is sensitive to age and education ${ }^{8,17}$, and some studies also suggest a gender effect, although these results have been inconsistent ${ }^{8,16,17}$.

Another important issue that should be considered when analyzing the demands of phonemic fluency tests is a developmental one, because the demands may differ depending on the age of the individual being assessed. In a sample of individuals aged 6-15 years, Tallberg et al. ${ }^{11}$ found significant positive associations between age and a) the number of correct answers, b) the effective use of phonological or semantic switching, and c) clustering strategies. Also, Hurks ${ }^{18}$ found that an instruction in semantic clustering could impact verbal fluency performance in the older children in her sample, but not in the younger children, for whom the implementation of the new strategy appeared to be difficult. This result suggests a relationship between age and the strategy used to solve the task.

Improvement across age in phonemic fluency test performance may be due, at least partially, to the development of EFs, because evidence suggests that EFs develop throughout childhood and adolescence until early adulthood. Thus, EFs can contribute in different ways to phonemic fluency tasks to the extent that EFs themselves develop. Moreover, evidence also supports the notion that different executive abilities develop in different ways ${ }^{4,19,20}$, and that the interrelationships between EFs appear to change throughout the developmental process in a way that suggests that these abilities are more interdependent in children and become more differentiated in early adolescence ${ }^{21}$ In other words, whereas in children the associations between EFs tend to be higher, in older children and teenagers these relationships are only low to moderate. Hence, in childhood and adolescence, EFs can be immature; during such stages, the partial contribution of each process in generating FAS solutions can be distinct from that observed in adults.

In this sense, the objective of this study was to investigate the relative contributions of EFs to FAS performance using a sample of children and teenagers (Group 1, children from grades 1-4; Group 2, teenagers from grades 5-8). We also considered age and gender effects on performance and predicted that differential abilities could contribute to FAS performance in each group, reflecting changes in solution strategies as a result of EF development. The study can contribute to our understanding of what is being measured by the FAS and how task demands on EFs change with age.

\section{METHODS}

\section{Participants}

Initially, we tested 495 children and teenagers aged 6-16 years recruited at two public schools in the state of Sao Paulo, Brazil. Owing to discrepancies between age and school grade, we excluded participants who had either repeated grades or had started school late relative to their peers. As a result, 413 children and teenagers aged 6-14 years (mean $[\mathrm{M}]=9.74$; standard deviation $[\mathrm{SD}]=2.40$ ) who attended grades $1-8$ of two public elementary schools comprised the final sample.

Although no formal testing was performed to rule out intellectual disability beyond screening for discrepancies between age and school grade (grade retention), no students with mental disabilities or non-corrected sensory disorders were included in the sample, as assessed by records and information provided by the teachers of the participants and students' handbooks, information that is used in eventual referrals to the specialized educational services for students who have some disability.

To analyze the different contributions of EFs, age and gender as a function of participants' developmental stage, we divided them into two groups: Group 1 comprised children from grades 1-4 and Group 2 comprised teenagers from grades $5-8$. This division by school grade was justified for some studies in a review by Strauss et al. ${ }^{10}$, in which education accounted for more variance than did age with respect to fluency task performance. Group 1 comprised 263 children aged 6-10 years ( $\mathrm{M}=8.21$; $\mathrm{SD}=1.26), 127$ (48.3\%) of whom were male. Group 2 comprised 150 teenagers aged 10-14 years $(\mathrm{M}=12.43$; $\mathrm{SD}=1.29), 63(42.0 \%)$ of whom were male. Distribution by age and school grade in each group is shown in Table 1. 


\section{Instruments}

Cancellation Attention Test (CAtT $)^{22}$. The CAtT assesses selective attention (Parts 1 and 2) and selective attention and shifting (Part 3) in a test of visual searching. The test consists of three matrices with a target and 300 stimuli (geometric shapes) in each matrix. Similar to classic cancellation paradigms, the participant identifies and marks stimuli that are similar to the target. Each matrix has a fixed time of $1 \mathrm{~min}$. The total number of correct answers in each part of the test was used as the score (Figure 1).

Auditory Working Memory Test (AWMT) ${ }^{23}$. The AWMT is a computerized test that evaluates auditory working

\section{Table 1. Distribution by age, school grade and group.}

\begin{tabular}{lcc}
\hline & \multicolumn{2}{c}{ No. of participants } \\
\cline { 2 - 3 } Age (years) & Group 1 & Group 2 \\
6 & 22 & - \\
7 & 66 & - \\
8 & 65 & - \\
9 & 55 & - \\
10 & 55 & 11 \\
11 & - & 32 \\
12 & - & 29 \\
13 & - & 37 \\
14 & - & 41 \\
School grade & & \\
1 & 61 & - \\
2 & 71 & - \\
3 & 48 & - \\
4 & 83 & - \\
5 & - & 38 \\
6 & - & 22 \\
7 & - & 41 \\
8 & - & 49 \\
\hline
\end{tabular}

memory (AWM). The software emits digitized voice sequences that consist of 2-10 words and numbers. The task is, first, to repeat the words in the sequence and, then, to repeat the numbers in increasing order. For example, if the stimulus is "three - bird - one - rain," then the correct response is "bird rain - one - three." The score is based on the number of correct sequences supplied.

Visual Working Memory Test (VWMT) ${ }^{23}$. The VWMT is a computerized test that assesses visual working memory. On a computer screen, one $3 \times 3$ matrix is shown which contains a stimulus in a single cell. Spatial manipulations, represented by arrows that indicate the direction of each move, are then shown on the screen. The participant has to imagine the stimulus moving across the matrix and select its final position. The task increases in difficulty until four matrices are shown on the same screen. The score is the number of correct answers supplied (Figure 2).

Trail Making Test (TMT) ${ }^{24}$. The TMT assesses cognitive flexibility. We used the Brazilian adaptation ${ }^{25}$. The task comprises items (letters and numbers) that must be alternately connected in sequence over a 1-minute period. The score is the number of sequences supplied (i.e., the number of items connected correctly) in each part (A and B).

Semantic Generation Test $(\mathrm{SeGeT})^{26}$. The SeGeT is a computerized test that measures inhibitory control (IC) ${ }^{27}$. The subject is asked to name an action that is semantically associated with drawings (nouns) that appear on a computer screen. The nouns can be low-selection (60 items), meaning that they evoke just one word (e.g., scissors is usually associated with the verb cut), or they can be high-selection (60 items), meaning that they can evoke a list of words (e.g., string, which can be associated with the words lace, tie, leap, or roll up). The differential analysis of performance based on the low- and high-selection conditions (performance on

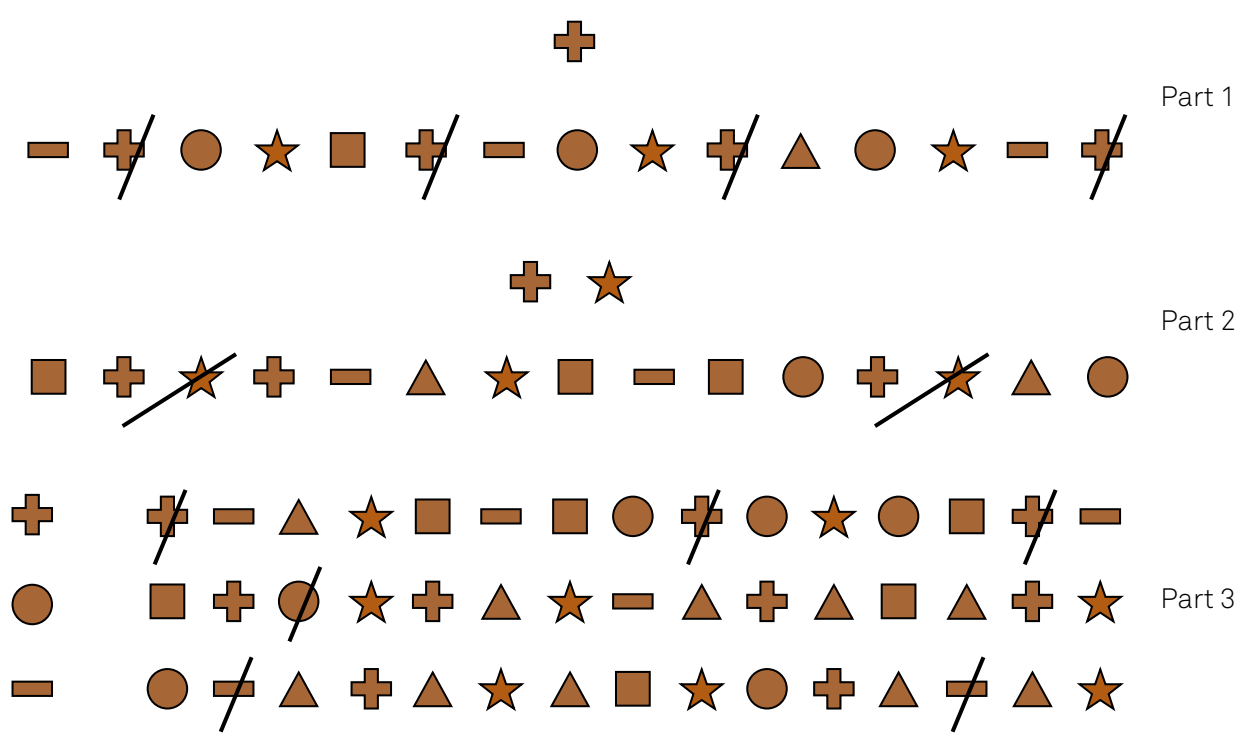

Figure 1. Examples of the required tasks in each part of the Cancellation Attention Test. 


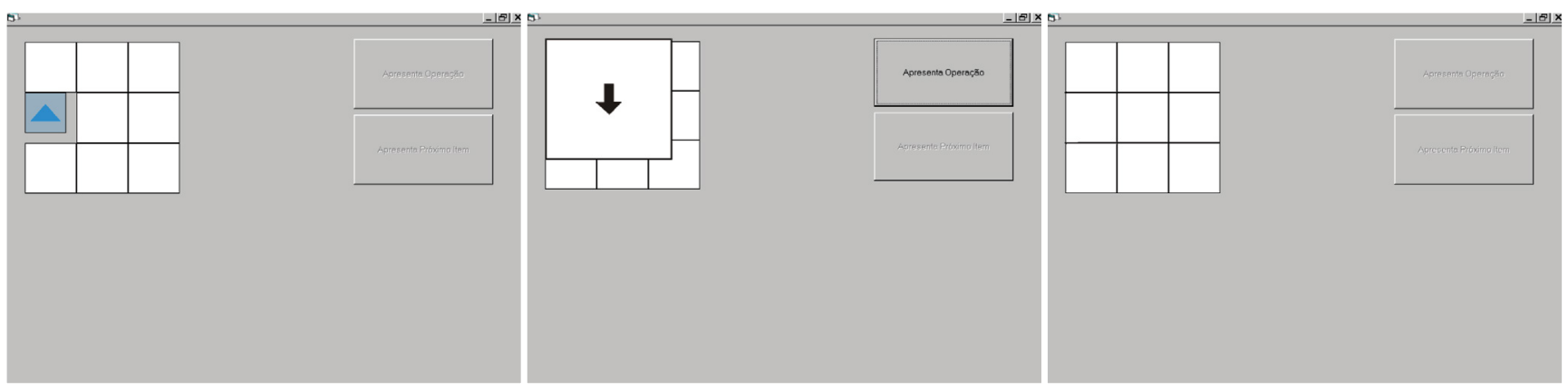

Figure 2. The sequence of screens presented for one item of the Visual Working Memory Test with one matrix task.

high-selection condition minus performance on low-selection condition) provides a score and reaction time (RT) interference index. Therefore, the measures used are the interference effects for score and $\mathrm{RT}^{24}$.

FAS Verbal Fluency Test (FAS) ${ }^{28}$. The computerized FAS version was used ${ }^{29}$ to evaluate the capacity of verbal fluency. The individual has to express the maximum possible number of words starting with " $F$ " over a 1-minute period. Then, the procedure is repeated with the letters "A" and "S." In this study, only the total score was adopted for analysis, which corresponds to the correct number of words given in the three parts of the task. Proper nouns were not allowed.

All of the tests were selected based on their psychometric proprieties as validated in samples of Brazilian children and teenagers ${ }^{4,30,31}$. The CAtT and TMT are available and published in Brazil 22,25 . The other tests were obtained from those who devised them.

\section{Procedure}

The project was approved by the Ethics Research Committee. A consent form was sent to the School Board of Directors and students' guardians. The tests took place in a classroom during regular school hours. Data collection began with administration of the collective tests (CAtT and TMT) over two sessions. The other tests were applied in individual sessions for a total of four evaluation sessions for each participant, with an average time of $20 \mathrm{~min}$ per session. The order of the tests was counterbalanced, and only one test per day was administered to each participant.

\section{Statistical analyses}

A Pearson's correlation analysis was performed between the predictive variables in each group. Multiple linear regression analyses were performed to determine which EF variables predicted FAS performance while controlling for age and gender, the latter of which was entered in the analysis as a dummy variable (0 - male; 1 - female). In our analyses, we considered Groups 1 and 2 independently so that we could also determine whether demands or solution strategies changed as a function of grade. The independent or predictive variables equated to the performance in each part of the CAtT, AWMT, VWMT and SeGeT (considering score and RT interference measures separately) and the sequences supplied in Parts A and B of the TMT. The Enter method was used to explore the contributions of each variable. In Table 2-4, significant results are shown in bold.

\section{RESULTS}

Table 2 shows the correlations between predictive variables (considering EF measures only). In both groups, despite statistical significance, correlations between measures tended to be low to moderate ( $r=0.14-0.46)$, highlighting that it could be difficult to group them into factors. So, the use of individual variables in the subsequent analyses is justified.

Concerning the prediction of FAS performance, regarding Group 1, age and gender were controlled at Step 1. The model adjustment was significant $(\mathrm{p}<0.001)$. In fact, the model had a significant effect on FAS performance, explaining up to $32.4 \%$ of the variance in test performance. However, although age was a significant predictor of FAS performance, gender had only a marginal effect. This finding indicated that, indeed, controlling for these variables - mainly age - led to a better data fit. All of the EF measures were then included in the regression. The model adjustment was significant $(\mathrm{p}<0.001)$, and EF measures were found to increase the explanatory power of the model to $38 \%$. In this model, age remained an important predictor of FAS performance $(~(\beta=0.35, p<0.001)$, but gender did not. The selective aspect of attention and shifting ( $\beta=0.26, p=0.002$ ) and the AWM measure $(\beta=0.16$, $\mathrm{p}=0.023$ ) significantly contributed to FAS performance after controlling for age and gender (Table 3).

The same procedure was repeated for Group 2. At Step 1 , age and gender were entered as controlled variables and the model showed significant adjustment $(\mathrm{p}<0.001)$. Age and gender had a significant effect on FAS performance, explaining up to $12.3 \%$ of the variance in test performance, indicating that controlling for these variables led to a better data fit. All of the EF measures were then included in the regression. 
Table 2. Correlation matrix between the predictive variables in each group.

\begin{tabular}{|c|c|c|c|c|c|c|c|c|c|c|}
\hline & & & AWMT & VWMT & SeGeT (score) & SeGeT (RT) & TMT-A & TMT-B & CAtT-1 & CAtT-2 \\
\hline \multirow[t]{16}{*}{ Group 1} & VWMT & $r$ & 0.33 & & & & & & & \\
\hline & & $p$ & 0.000 & & & & & & & \\
\hline & SeGeT (score) & $r$ & 0.02 & 0.073 & & & & & & \\
\hline & & $p$ & 0.819 & 0.268 & & & & & & \\
\hline & SeGeT (RT) & $r$ & 0.06 & 0.03 & 0.17 & & & & & \\
\hline & & $p$ & 0.332 & 0.687 & 0.007 & & & & & \\
\hline & TMT-A & $r$ & 0.33 & 0.22 & -0.04 & 0.03 & & & & \\
\hline & & $p$ & 0.000 & 0.001 & 0.592 & 0.671 & & & & \\
\hline & TMT-B & $r$ & 0.29 & 0.27 & 0.11 & 0.11 & 0.36 & & & \\
\hline & & $p$ & 0.000 & 0.000 & 0.102 & 0.116 & 0.000 & & & \\
\hline & CAtT-1 & $r$ & 0.18 & 0.08 & 0.04 & 0.11 & 0.14 & 0.26 & & \\
\hline & & $p$ & 0.006 & 0.198 & 0.575 & 0.106 & 0.030 & 0.000 & & \\
\hline & CAtT-2 & $r$ & 0.35 & 0.23 & 0.11 & 0.12 & 0.29 & 0.35 & 0.38 & \\
\hline & & $p$ & 0.000 & 0.000 & 0.089 & 0.079 & 0.000 & 0.000 & 0.000 & \\
\hline & CAtT-3 & $r$ & 0.46 & 0.33 & 0.03 & 0.01 & 0.40 & 0.34 & 0.36 & 0.46 \\
\hline & & $p$ & 0.000 & 0.000 & 0.677 & 0.941 & 0.000 & 0.000 & 0.000 & 0.000 \\
\hline \multirow[t]{16}{*}{ Group 2} & VWMT & $r$ & 0.41 & & & & & & & \\
\hline & & $p$ & 0.000 & & & & & & & \\
\hline & SeGeT (score) & $r$ & 0.07 & 0.11 & & & & & & \\
\hline & & $p$ & 0.428 & 0.188 & & & & & & \\
\hline & SeGeT (RT) & $r$ & -0.09 & -0.01 & -0.16 & & & & & \\
\hline & & $p$ & 0.297 & 0.897 & 0.049 & & & & & \\
\hline & TMT-A & $r$ & 0.12 & 0.14 & 0.05 & -0.02 & & & & \\
\hline & & $p$ & 0.186 & 0.113 & 0.580 & 0.880 & & & & \\
\hline & TMT-B & $r$ & 0.20 & 0.29 & 0.22 & -0.02 & 0.41 & & & \\
\hline & & $p$ & 0.021 & 0.001 & 0.011 & 0.831 & 0.000 & & & \\
\hline & CAtT-1 & $r$ & 0.01 & 0.06 & 0.07 & -0.05 & -0.04 & 0.05 & & \\
\hline & & $p$ & 0.992 & 0.533 & 0.406 & 0.586 & 0.616 & 0.525 & & \\
\hline & CAtT-2 & $r$ & 0.25 & 0.13 & 0.07 & -0.02 & 0.22 & 0.21 & 0.39 & \\
\hline & & $p$ & 0.004 & 0.134 & 0.439 & 0.781 & 0.008 & 0.011 & 0.000 & \\
\hline & CAtT-3 & $r$ & 0.17 & 0.32 & -0.04 & 0.08 & 0.10 & 0.21 & 0.35 & 0.31 \\
\hline & & $p$ & 0.046 & 0.000 & 0.688 & 0.359 & 0.240 & 0.013 & 0.000 & 0.000 \\
\hline
\end{tabular}

AWMT: Auditory Working Test; VWMT:Visual Working Memory Test; SeGeT: Semantic Generation Test; RT: reaction time; TMT: Trail Making Test (Part A and B); CAtT: Cancellation Attention Test (Part 1:2 and 3).

The model adjustment was significant $(\mathrm{p}<0.001)$, and the inclusion of EFs improved the explanatory power of the model to $27.1 \%$. Although the gender effect continued to be significant ( $ß=0.23$, $p=0.005$ ), the age effect was not significant upon the inclusion of EF measures. The IC $(\beta=-0.29, p=0.001)$, AWM $(~ \beta=0.24, p=0.011)$ and selective attention and shifting measures ( $\beta=0.21, p=0.026$ ) contributed significantly to FAS performance in this group (Table 4).

\section{DISCUSSION}

Our results revealed the EF demands on FAS performance in a sample of children and teenagers. The impact of this finding is that we can have a better comprehension of what is indeed measured by the FAS, and about strategy changes in performance with age progression. In this way, the results suggest that different abilities, and also different rates of the same abilities, can predict FAS performance in Groups 1 and 2. Also, age and gender can impact performance differently in each group. For Group 1, age and, marginally, gender (girls outperformed boys), were part of the first model. With the inclusion of EF measures, the AWM and selective attention and shifting proved to be important predictors of the children's performances, despite the continued effect of age. For this group, regression coefficients associated with age, working memory and shifting measurements were positive, suggesting that there is an improvement in FAS performance with advancing age. Also, participants who performed better in the auditory working memory task as well as in focus attention and shifting obtained better FAS scores.

For Group 2, the first model showed that both age and gender could explain FAS performance. In a second set of analyses, after executive measures were entered, only a gender effect was maintained. Furthermore, AWM, shifting and IC were predictors of FAS performance. The regression 
Table 3. Group 1: standardized regression coefficients (b), $t$ and p statistics, and R2 and adjusted R2 for each measurement included in the regression models.

\begin{tabular}{|c|c|c|c|c|c|c|}
\hline \multicolumn{2}{|c|}{ Model } & \multirow[t]{2}{*}{ Standardized regression coefficient (b) } & \multirow{2}{*}{$\begin{array}{c}t \\
-3.426\end{array}$} & \multirow{2}{*}{$\frac{p}{0.001}$} & \multirow{2}{*}{$\begin{array}{c}R 2 \\
0.33\end{array}$} & \multirow{2}{*}{$\begin{array}{c}\text { Adjusted } R 2 \\
0.32\end{array}$} \\
\hline 1 & (Constant) & & & & & \\
\hline & Age (years) & 0.547 & 9.111 & 0.000 & & \\
\hline & Gender & 0.103 & 1.716 & 0.088 & & \\
\hline \multirow[t]{12}{*}{2} & (Constant) & & -1.186 & 0.237 & 0.41 & 0.38 \\
\hline & Age (years) & 0.348 & 4.632 & 0.000 & & \\
\hline & Gender & 0.062 & 0.966 & 0.335 & & \\
\hline & AWMT & 0.157 & 2.296 & 0.023 & & \\
\hline & VWMT & -0.078 & -1.174 & 0.242 & & \\
\hline & SeGeT (score) & 0.091 & 1.563 & 0.120 & & \\
\hline & SeGeT (RT) & -0.046 & -.792 & 0.429 & & \\
\hline & CAtT-1 & -0.041 & -.667 & 0.505 & & \\
\hline & CAtT-2 & -0.005 & -0.073 & 0.942 & & \\
\hline & CAtT-3 & 0.260 & 3.127 & 0.002 & & \\
\hline & TMT-A & 0.006 & 0.086 & 0.932 & & \\
\hline & TMT-B & 0.049 & 0.766 & 0.445 & & \\
\hline
\end{tabular}

Dependent variable:FAS.

Predictors: Age (years); Gender (0 - male; 1 - female); AWMT: total number of correct sequences in the Auditory Working Memory Test; VWMT: total number of correct items in the Visual Working Memory Test; SeGeT (score): interference score (performance on high-selection trials minus performance on low-selection trials) in the Semantic Generation Test; SeGeT (RT): interference reaction time in seconds (reaction time on high-selection trials minus reaction time on lowselection trials) in the Semantic Generation Test; CAtT-1: total number of correct answers in Part 1 of the Cancellation Attention Test; CAtT-2: total number of correct answers in Part 2 of the Cancellation Attention Test; CAtT-3: total number of correct answers in Part 3 of the Cancellation Attention Test; TMT-A: sequence score on Part A of the Trail Making Test; TMT-B: sequence score in Part B of the Trail Making Test.

Table 4. Group 2: standardized regression coefficients (b), $t$ and $p$ statistics, and R2 and adjusted R2 for each measurement included in the regression models.

\begin{tabular}{|c|c|c|c|c|c|c|}
\hline \multicolumn{2}{|c|}{ Model } & \multirow[t]{2}{*}{ Standardized regression coefficient (b) } & \multirow{2}{*}{$\frac{t}{-0.434}$} & \multirow{2}{*}{$\frac{p}{0.665}$} & \multirow{2}{*}{$\frac{R 2}{0.14}$} & \multirow{2}{*}{$\begin{array}{c}\text { Adjusted } R 2 \\
0.12\end{array}$} \\
\hline 1 & (Constant) & & & & & \\
\hline & Age (years) & 0.318 & 3.730 & 0.000 & & \\
\hline & Gender & 0.179 & 2.106 & 0.037 & & \\
\hline \multirow[t]{12}{*}{2} & (Constant) & & -1.070 & 0.287 & 0.34 & 0.27 \\
\hline & Age (years) & 0.145 & 1.629 & 0.106 & & \\
\hline & Gender & 0.231 & 2.861 & 0.005 & & \\
\hline & AWMT & 0.235 & 2.592 & 0.011 & & \\
\hline & VWMT & 0.065 & 0.717 & 0.475 & & \\
\hline & SeGeT (score) & $-0,033$ & -0.404 & 0.687 & & \\
\hline & SeGeT (RT) & -0.290 & -3.549 & 0.001 & & \\
\hline & CAtT-1 & -0.023 & -0.243 & 0.809 & & \\
\hline & CAtT-2 & -0.030 & -0.305 & 0.761 & & \\
\hline & CAtT-3 & 0.212 & 2.256 & 0.026 & & \\
\hline & TMT-A & 0.133 & 1.499 & 0.137 & & \\
\hline & TMT-B & -0.109 & -1.180 & 0.240 & & \\
\hline
\end{tabular}

AWMT: Auditory Working Memory Test; VWMT: Visual Working Memory Test; CAtT: Cancellation Attention Test (Part 1: 2 and 3); RT: reaction time; SeGeT: Semantic Generation Test; TMT: Trail Making Test (Part A and B).

coefficients associated with gender, as well as with AWM and shifting measurements, were positive, i.e., girls performed better than boys, and those who had higher scores in the AWM and shifting measurements tended to have the best results on the FAS. The regression coefficient associated with the IC measurement was negative. This score refers to an RT interference measure (i.e., the RT in the high-selection condition minus the RT in the low-selection condition on the SeGeT). The greater this difference, the greater the interference effect - i.e., the participant needed more time to inhibit competitors and answer the high-selection items. The negative regression coefficient means that participants with less interference RT, reflecting better inhibition, also had better performance on the FAS. One could argue that participants with lower IC might generate more words and do better on the FAS, but that does not seem to be the case, at least considering the number of correct answers provided. However, the influence of inhibition on the 
total number of answers (correct and incorrect) should be further investigated.

These findings partially corroborate previous studies of adults and the elderly that have pointed to the roles of working memory, especially the auditory subsystem, and, to some extent, inhibition and shifting, as important abilities involved in the FAS ${ }^{3,8,13,14}$. The insertion of these EFs in the explicative model can be understood in terms of task requirements on processing information. For example, to verbalize the answers while the test is carried out, it is necessary to access long-term memory to remember a specific word, record the previous verbalized words to avoid repetitions, and continuously update new entries in the working memory. Besides, it is also necessary to shift between new clusters and inhibit incorrect items.

Beyond this general understanding, we also found differential contributions to FAS performance in each of our groups. In fact, although Bolla et al. ${ }^{16}$ reported gender effects, other studies have not ${ }^{8,17}$. This can be attributed to the samples used in each study. We found that gender was not a significant predictor of FAS performance in Group 1, but it was a significant predictor in Group 2, which comprised older children and teenagers. This means that, for children up to 10 years of age (Group 1), gender does not affect FAS performance, but with age progression and, maybe, with EF development and differentiation, gender becomes an important variable in performance. On the other hand, age remained a significant predictor of FAS performance after inclusion of EF measures in Group 1, but not in Group 2. The magnitude of the age effect on EF development appears to be generally large in younger children (5-7 years), moderate in older children (8-15 years), and quite small after that ${ }^{20}$. Data regarding the improvement in EF performance as a function of age can be found in the study by Dias et al. ${ }^{4}$.

Additionally, regarding EF abilities, different demands (and explanatory powers) were associated with FAS performance in each group. Although the AWM and selective attention and shifting played a role in both groups' performances, IC only contributed to FAS performance in Group 2; in other words, older children can use different strategies to solve these tasks ${ }^{11}$. It should be mentioned that, despite the finding that Group 1 results could be better explained by the final model than could those in Group 2, when EF measures were entered it led to a slight increase in the explanatory power of the model. In contrast, when EF measures were entered, the model for Group 2 demonstrated a more consistent improvement in explanatory power beyond age and gender. In other words, older children and adolescents seem to show: a) more differentiation in the contributions of EF components relative to FAS performance, especially inhibitory control, beyond the effects of working memory and selective attention and shifting; and b) a greater effect of these contributions relative to younger children. We can suppose that further differentiation of EF components occurs across development ${ }^{12,21,32}$, along with verbal fluency becoming more dependent on such components; more elementary abilities (such as vocabulary) become more stable over time, and differences in performance across age become attributable to more complex abilities, such as EFs. Indeed, some studies have found a relationship between vocabulary and phonemic fluency tasks in children aged 7-9 years ${ }^{32}$, but not in youths ${ }^{33}$. Vocabulary demands should be addressed and controlled in future research. Furthermore, the explanatory powers of the models were modest. This suggests that other demands of the FAS (executive and non-executive) remain to be investigated.

Some limitations of the study should be mentioned, such as the fact that our sample consisted only of students from public schools and did not include a screening or cognitive assessment, although information about the students was provided by the schools. Despite these gaps, the study contributed to our understanding of what is being measured by the FAS. In addition, our research showed that gender and age can affect performance differentially when considering specific age groups. Moreover, our investigation revealed that EF demands on FAS performance can change with age, which most likely reflects changes in the strategies used for task resolution.

\section{References}

1. Rabin LA, Barr WB, Burton LA. Assessment practices of clinical neuropsychologists in the United States and Canada: a survey of INS, NAN, and APA Division 40 members. Arch Clin Neuropsychol 2005;20:33-65.

2. Passos VMA, Giatti L, Barreto SM, et al. Verbal fluency tests reliability in a Brazilian multicentric study, ELSA-Brasil. Arq Neuropsiquiatr 2011;69:814-816.

3. Malloy-Diniz LF, Sedo M, Fuentes D, Leite WB. Neuropsicologia das funções executivas. In: Fuentes D, Malloy-Diniz LF, Camargo CHP, Cosenza RM (Eds). Neuropsicologia: Teoria e Prática. Porto Alegre: Artmed, 2008:187-206.
4

Dias NM, Menezes A, Seabra AG. Age differences in executive functions within a sample of Brazilian children and adolescents. Span J Psychol 2013;16:1-14.

5. Goncalves HA, Mohr RM, Moraes AL, Siqueira LS, Prando ML, Fonseca RP. Componentes atencionais e de funções executivas em meninos com TDAH: dados de uma bateria neuropsicológica flexivel. J Bras Psiquiatr 2013;62:13-21.

6. Novaretti TMS, Radanovic M, Nitrini R. Screening for cognitive impairment in late onset depression in a Brazilian sample using the BBRC-EDU. Dement Neuropsychol 2012;6:85-90. 
Freitas PM, Cardoso TGS, Siquara GM, Freitas LMA, Silva, VS. Avaliação neuropsicológica dos déficits cognitivos e comportamentais associados à aprendizagem em crianças de 4 a 8 anos. Estudos IAT 2012;2:63-83.

8. Lezak MD, Howieson DB, Loring DW. Neuropsychological Assessment. 4th ed. New York: Oxford University Press, 2004.

9. Golden CJ, Espe-Pfeifer P, Wachsler-Felder J. Neuropsychological Interpretation of Objective Psychological Tests (Critical Issues in Neuropsychology). New York: Kluwer, 2002.

10. Strauss E, Sherman EMS, Spreen O. A Compendium of Neuropsychological Tests: Administration, Norms, and Commentary. 3rd ed. New York: Oxford University Press, 2006.

11. Tallberg IM, Carlsson S, Lieberman M. Children's word fluency strategies. Scand J Psychol 2011;52:35-42.

12. Miyake A, Friedman NP, Emerson MJ, Witzki AH, Howerter A, Wager T. The unity and diversity of executive functions and their contributions to complex "frontal lobe" tasks: A latent variable analysis. Cogn Psychol 2000;41:49-100

13. Rende B, Ramsberger G, Miyake A. Commonalities and differences in the working memory components underlying letter and category fluency tasks: a dual-task investigation. Neuropsychology 2002;16:309-321.

14. Troyer AK, Moscovitch M, Winocur G. Clustering and switching as two components of verbal fluency: evidence from younger and older healthy adults. Neuropsychology 1997;11:138-146.

15. Szatkowska I, Grabowska A, Szymanska O. Phonological and semantic fluencies are mediated by different regions of the prefrontal cortex. Acta Neurobiol Exp (Wars) 2000;60:503-508.

16. Bolla KI, Lindgren KN, Bonaccorsy C, Bleecker ML. Predictors of verbal fluency (FAS) in the healthy elderly. J Clin Psychol 1990;46:623-628.

17. Barry D, Batesb ME, Labouvieb E. FAS and CFL forms of verbal fluency differ in difficulty: a meta-analytic study. Appl Neuropsychol 2008;15:97-106.

18. HurksPP.Doesinstructioninsemanticclusteringandswitchingenhance verbal fluency in children? Clin Neuropsychol 2012;26:1019-1037.

19. Best JR, Miller PH.A developmental perspective on executive function. Child Dev 2010;81:1641-1660.

20. Best JR, Miller P, Naglieri JA. Relations between executive function and academic achievement from ages 5 to 17 in a large, representative national sample. Learn Individ Differ 2011;21:327-336.
21. Cuevas RR, Alanís T. Exploring the interrelation of executive functions during child development. J Int Neuropsychol Soc 2008;14:56-56.

22. Montiel JM, Seabra AG. Teste de Atenção por Cancelamento [Cancellation Attention Test]. In: Seabra AG, Dias NM (Eds.), Avaliação neuropsicológica cognitiva: atenção e funções executivas. Vol. 1. [Cognitive Neuropsychological Assessment: Attention and Executive Functions]. São Paulo, Brazil: Memnon, 2012:47-56.

23. Primi R. Bateria Informatizada de Capacidades Cognitivas [Computerized Battery of Cognitive Skills]. Software. Itatiba, Brazil: São Francisco University, 2002.

24. Gil R. Neuropsicologia. São Paulo, Brazil: Editora Santos, 2002.

25. Montiel J, Seabra AG. Teste de trilhas [trail making test]. In: Seabra AG, Dias NM (Eds). Avaliação neuropsicológica cognitiva: atenção e funções executivas. Vol. 1. [Cognitive Neuropsychological Assessment: Attention and Executive Functions]. São Paulo, Brazil: Memnon, 2012:69-75.

26. Seabra AG, Cozza H, Capovilla FC, Macedo EC, Dias NM. Avaliação de controle inibitório em crianças: Teste de Geração Semântica [assessment of inhibitory control in children:the Semantic Generation Test]. In:Seabra AG, Capovilla FC (Eds). Teoria e Pesquisa em Avaliação Neuropsicológica [Theory and Practice in Neuropsychological Assessment]. 2nd ed. São Paulo, Brazil: Memnon, 2009:69-75.

27. Thompson-Schill SL, Swich D, Farah MJ, D’Exposito M, Kan IP, Knight RT. Verb generation in patients with focal frontal lesions: a neuropsychological test of neuroimaging findings. PNAS 1998;95:55-60.

28. Benton AL, Hamsher KD. Multilingual Aphasia Examination. Iowa City, IA: AJA Associates, 1989.

29. Seabra AG. Teste de Fluência Verbal FAS. Software. São Paulo, Brazil: Mackenzie Presbyterian University, in press.

30. Assef ECS, Capovilla AGS, Capovilla FC. Computerized Stroop Test to assess selective attention in children with attention deficit hyperactivity disorder. Span J Psychol 2007;10:33-40.

31. Capovilla AGS, Dias NM, Trevisan BT, Montiel JM, Andrade AM. Validity of neuropsychological instruments for attention assessment in Brazilian children. J Int Neuropsychol Soc 2008;14:7-8.

32. Brydges CR, Reid CL, Fox AM, Anderson M. A unitary executive function predicts intelligence in children. Intelligence 2012;40:458-469.

33. Ross TP, Calhoum E, Cox T, Wenner C, Kono W, Pleasant M. The reliability and validity of qualitative scores for the Controlled Oral Word Association Test. Arch Clin Neuropsychol 2007;22:475-488. 